\title{
Rancang Bangun Aplikasi Game Edukasi Pengenalan Bahasa Daerah Galela Untuk Anak Tingkat Sekolah Dasar
}

\author{
M Tasyrik Ando ${ }^{1)}$, Virginia Tulenan ${ }^{2)}$, Steven Sentinuwo ${ }^{3)}$ \\ 1,2,3 Program Studi Teknik Informatika, Fakultas Teknik, Universitas Sam Ratulangi \\ E-mail : ikhyando@gmail.com ${ }^{1)}$, virginia.tulenan@ unsrat.ac.id ${ }^{2)}$, steven@ unsrat.ac.id ${ }^{3}$
}

\begin{abstract}
Abstrak - Bahasa daerah adalah suatu bahasa yang dituturkan di suatu wilayah dalam sebuah negara kebangsaan pada suatu daerah kecil, negara bagian federal, provinsi, atau daerah yang lebih luas. Seiring dengan berjalannya waktu keanekaragaman bahasa daerah yang ada di Indonesia, perlahan bisa tersingkir bahkan lebih buruk lagi akan hilang bila tidak diperkenalkan dengan budaya sejak dini. Tujuan pembuatan aplikasi game edukasi pengenalan bahasa daerah galela untuk anak tingkat sekolah dasar adalah untuk membantu memperkenalkan bahasa galela kepada anak - anak sd khususnya usia 6-11 tahun, agar kelak anak - anak dari galela dapat mengetahui dan mengenal secara dini bahasa daerahnya sendiri. Fitur - fitur yang terdapat pada aplikasi ini dibuat menggunakan aplikasi Unity. Metode Penelitian yang digunakan pada aplikasi game edukasi pengenalan bahasa daerah galela untuk anak tingkat sekolah dasar yaitu metode Rapid Game Prototyping yang merupakan metode gabungan antara proses rekayasa perangkat lunak dengan metode game desain. Perancangan pembuatan game ini dilakukan dengan membuat model yang menjelaskan setiap kegiatana secara detail dengan menggunakan Unified Modelling Languange (UML). Kesimpulannya adalah game edukasi bahasa galela adalah sebuah game yang mengandung nilai - nilai pendidikan mengenai kebudayaan daerah khususnya bahasa daerah galela.
\end{abstract}

Kata Kunci : Game, Edukasi, Anak, Bahasa

Daerah, Galela

\section{Pendahuluan}

Bahasa dapat diartikan sebagai alat untuk menyampaikan sesuatu yang terlintas di dalam hati. Namun, lebih jauh bahasa adalah alat untuk berinteraksi atau alat untuk berkomunikasi, dalam arti alat untuk menyampaikan pikiran, gagasan, konsep atau perasaan. Sedangkan pada bahasa daerah ialah suatu penuturan yang dipergunakan untuk berinteraksi antar daerah tertentu saja, sehingga tidak memungkinkan daerah lain untuk mengerti akan daerah lainnya.

Dengan berjalannya waktu keanekaragaman bahasa daerah yang ada di Indonesia, perlahan bisa tersingkir bahkan lebih buruk lagi akan hilang bila tidak diperkenalkan dengan budaya sejak dini. Sebagai anak bangsa baiknya diperkenalkan sejak dini pengetahuan tentang bahasa daerahnya sendiri agar kelak dapat mempertahankan serta menjaga keanekaragam bahasa tersebut karena sebagai satu ciri khas dari daerah. Selain itu berdasarkan pengalaman saya bahwasanya bahasa yang dipakai di galela masih bahasa sehari - hari atau bahasa pasar sehingga perlahan - lahan anak - anak yang ada di galela bisa kehilangan jati diri atau dengan kata lain tidak bisa berbahasa daerahnya sendiri. Hal ini terjadi dikarenakan secara umum anak pada usia dini lebih tertarik pada dunia bersenang-senang dan bermain. Sehingga diperlukan suatu media dimana dapat membantu memperkenalkan bahasa daerahnya sendiri pada anak pada usai dini.

Dengan berkembangnya teknologi saat ini bermunculan berbagai jenis game yang mengandung unsur edukasi. Game merupakan salah satu teknologi informasi yang bisa dimanfaatkan sebagai sarana pembelajaran dimana prosesnya dapat dilakukan dengan konsep belajar sambil bermain . Teknologi tersebut dapat dijadikan pilihan untuk para orang tua untuk memperkenalkan bahasa daerah. Sehingga timbul ide menyelesaikan masalah tersebut dengan membangun aplikasi yang memberikan pengenalan tentang bahasa serta budaya daerah dengan judul "Rancang Bangun Aplikasi Game Edukasi Pengenalan Bahasa Daerah Galela Untuk Anak Tingkat Sekolah Dasar". Sehingga dengan adanya game edukasi mengenal bahasa daerah ini diharapkan dapat meningkatkan pengetahuan pada anak dalam mengenal bahasa daerahnya sendiri dan diharapkan suatu saat anak dapat menjaga ciri khas daerahnya tersebut.

\section{LANDASAN TEORI}

\section{A. Pengertian Game}

Game dapat diartikan sebagai kegiatan penyelesaian masalah, didekati dengan sikap yang menyenangkan, game juga sesuatu yang membuat pemain menemukan kesenangan dalam memainkannya. Game yang bagus adalah game yang dapat membuat pengguna berpartisipasi secara aktif dan mempunyai jumlah tantangan yang tepat, tidak terlalu sedikit atau terlalu banyak. Sikap orang ketika sedang bermain game, bisa saja berbeda ketika orang 
itu sedang tidak bermain game, karena ketika orang tersebut sedang bermain game maka dia akan merasa sedang berada di "dunia" yang game tersebut ciptakan.

Schell menyebutkan bahwa kebanyakan orang biasanya suka memecahkan masalah atau menghadapi tantangan. Game pasti menyediakan masalah dan tantangan untuk dihadapi oleh pengguna, jika game tidak menyediakan tantangan maka game tersebut akan kurang menyenangkan untuk dimainkan. Game juga menyediakan goals (tujuan) untuk pengguna, sehingga pengguna mempunyai tujuan dalam memainkan game tersebut, jika game tidak mempunyai goals mungkin pengguna akan menemukan bahwa game tersebut membosankan.

\section{B. Genre Game}

Gameplay dalam game dibedakan menurut genrenya yang sekarang ini sudah bermacam-macam. Genre juga mempunyai tugas untuk membatasi para perancang game untuk dapat berkreasi dalam ide yang lebih spesifik. Genre juga mempunyai tugas untuk membatasi para perancang game untuk dapat berkreasi dalam ide yang lebih spesifik. Di dalam satu game juga dapat mengandung lebih dari satu genre yang disebut dengan hybrid genre. Macam-macam genre game yaitu Action Games, Strategy games, Role-Playing Games, Sports Games, Racing/Driving Games, Simulation/Building Games, Flight and Other Simulations., Adventure Game, Edutaintment, Children's Games, Casual Games

\section{Unity $3 D$}

Unity salah satu game engine yang mudah digunakan, hanya membuat objek dan diberikan fungsi untuk menjalankan objek tersebut. Dalam setiap objek mempunyai variabel, variabel inilah yang harus dimengerti supaya dapat membuat game yang berkualitas. Berikut ini adalah bagian-bagian dalam Unity. Asset yang adalah tempat penyimpanan dalam Unity yang menyimpan suara, gambar, video, dan tekstur. Scenes adalah area yang berisikan kontenkonten dalam game, seperti membuat sebuah level, membuat menu, tampilan tunggu, dan sebagainya. Game Objects adalah barang yang ada di dalam assets yang dipindah ke dalam scenes, yang dapat digerakkan, diatur ukurannya dan diatur rotasinya. Components adalah reaksi baru, bagi objek seperti collision, memunculkan partikel, dan sebagainya. Script, yang dapat digunakan dalam unity ada tiga yaitu javascript, C\# dan BOO.

\section{Anak Usia Sekolah}

Menurut Gunarsa (2006), dengan memasuki dunia sekolah dan masyarakat, anak-anak dihadapkan pada tuntutan sosial yang baru, yang menyebabkan timbulnya harapan-harapan atas diri sendiri (self-expect-action) dan aspirasi-aspirasi baru, dengan lain perkataan akan muncul lebih banyak tuntutan dari lingkungan maupun dari dalam anak sendiri yang kesemuanya ingin dipenuhi. Beberapa ketrampilan yang perlu dimiliki anak pada fase ini meliputi antara lain: Ketrampilan menolong diri sendiri (self-help skills) : misalnya dalam hal mandi, berdandan, makan, sudah jarang atau bahkan tidak perlu ditolong lagi. Ketrampilan bantuan sosial (social-help skills) : anak mampu membantu dalam tugas-tugas rumah tangga seperti : menyapu, membersihkan rumah, mencuci dan sebagainya. Ketrampilan sekolah (school-skills) : meliputi penguasaan dalam hal akademik dan non akademik. Ketrampilan bermain (play- skills) : meliputi ktrampilan dam berbagai jenis permainan seperti main bola, mengendarai sepeda, catur, bulutangkis dan lainlain.

\section{E. Galela}

Galela adalah kelompok etnik dengan wilayah asalnya di pulau Halmahera, mereka berdiam terutama di pantai bagian utara pulau Halmahera itu, yaitu di sekitar Teluk Galela. Kini wilayah asal tersebut merupakan wilayah administratif Kecamatan Galela, dalam wilayah Provinsi Maluku Utara. Sebagai satu kelompok etnik mereka memiliki bahasa sendiri yakni bahasa Galela. Sumber tertentu mengatakan bahwa bahasa ini merupakan salah satu dari 10 bahasa besar dalam kelompok bahasa yang disebut Siwalima atau satu diantara ratusan bahasa yang ada di Maluku.

Ahli bahasa membuat rincian lagi dimana bahasa Galela termasuk Keluarga bahasa Halmahera, yang termasuk rumpun bahasa Halmahera Utara bagian barat. Rumpun ini masih terbagi dua cabang bahasa, yakni bahasa Galela dan bahasa Ibu.

\section{F. Metode Rapid Game Prototyping}

Pada penelitian ini, penulis menggunakan metode rapid game prototyping (lihat gambar 1) adalah metode hasil modifikasi dari metode pengembangan perangkat lunak cepat pemrograman ekstrem.

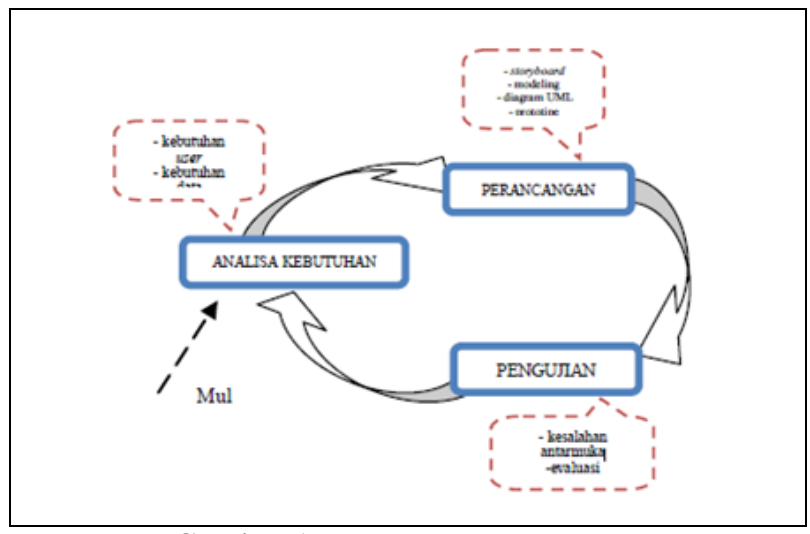

Gambar 1 Proses Rapid Game Prototyping

Terdapat 3 proses dalam metode rapid game prototyping ini:

- Analisa Kebutuhan

Analisa kebutuhan dilakukan untuk mengetahui kebutuhan user, kebutuhan data dan user stories.

- Perancangan

Pada proses ini yang dilakukan adalah membuat storyboard, merancang tampilan dari game edukasi O'Galelano, diagram uml yaitu use case dan activity diagram kemudian prototyping 
- Pengujian

Game edukasi yang telah selesai dibuat selanjutnya diuji menggunakan teknik pengujian perangkat lunak kotam hitam (Black Box) kemudian dilakukan evaluasi

\section{METODELOGI PENELITIAN}

\section{A. Tahap Analisa Kebutuhan}

Tahap ini bertujuan mengidentifikasi kebutuhan user, kebutuhan data dan user stories.

1. Kebutuhan user, digunakan sebagai acuan dalam membuat user interface dan fitu-fitur dalam game yang dikumpulkan dengan membagikan kuisioner yang berisikan beberapa pertanyaan kepada 40 orang responden pada bulan september tahun 2016 targetnya kepada anak - anak usia 6 sampai 11 tahun, lokasi penelitian di Kecamatan Galela Desa Soasio

2. Kebutuhan Data, pengumpulan data dalam hal ini berisikan pengetahuan yang berhubungan dengan aplikasi yang dibuat, seperti mengamati objek dan mengambil sampel berupa nama dari beberapa objek seperti angka, anggota tubuh, hewan, buah, warna, kata kerja, kata sifat, gambar dan audio yang kemudian akan digunakan didalam aplikasi.

3. User Stories

a. Konsep Game, game ini akan dibuat dalam genre Educational Game, karena game edukasi mari mengenal "Bahasa Galela" ini pada game 1 pemain tidak langsung diarahkan untuk bermain game tetapi ditampilkan terlebih dahulu pembelajaran pengenalan bahasa galela berdasarkan kategori yang tersedia, beserta audio cara pengucapannya. Tujuannya adalah pemain dapat mempelajari terlebih dahulu nama nama dalam bahasa galela dari setiap kategori yang akan dicocokkan dengan gambar yang telah tersedia. Sedangkan pada game 2 pemain langsung diarahkan untuk bermain, pemain harus menjawab soal - soal latihan yang ada pada game 2 ini.

b. Mekanisme, mekanisme yang digunakan dalam game ini yaitu pada setiap kategori yang ada pada game edukasi ini pemain harus menekan tombol panah yang ada untuk bisa melihat dan belajar bahasa galela dan ada juga tombol suara sehingga pemain bisa menekan untuk mendengar suara bahasa galela dari gambar yang dilihat.

c. Objektif Game,Pemain harus belajar semua kategori yang ada pada game ini, agar supaya pemain bisa menyelesaikan soal - soal yang terdapat pada menu latihan dengan benar.

d. Fitur Game,

- Pemain dapat memilih kategori yang disukai untuk belajar mengenal bahasa galela
- Saat pemain bermain pada game edukasi ini, pemain dapat menekan tombol suara untuk mendengar suara bahasa galela dari gambar yang dilihat

- Pemain juga bisa dapat mengevaluasi hasil belajar dari kategori yang ada pada soal - soal latihan yang ada pada game edukasi ini.

e. Target Pemain, game ini ditargetkan untuk anak - anak usia 6 - 11 tahun.

\section{B. Tahap Perancangan}

1. Storyboard

Pada tahap ini dibuatlah storyboard dari masing - masing scene permainan, Salah satu storyboard dapat dilihat pada gambar 2

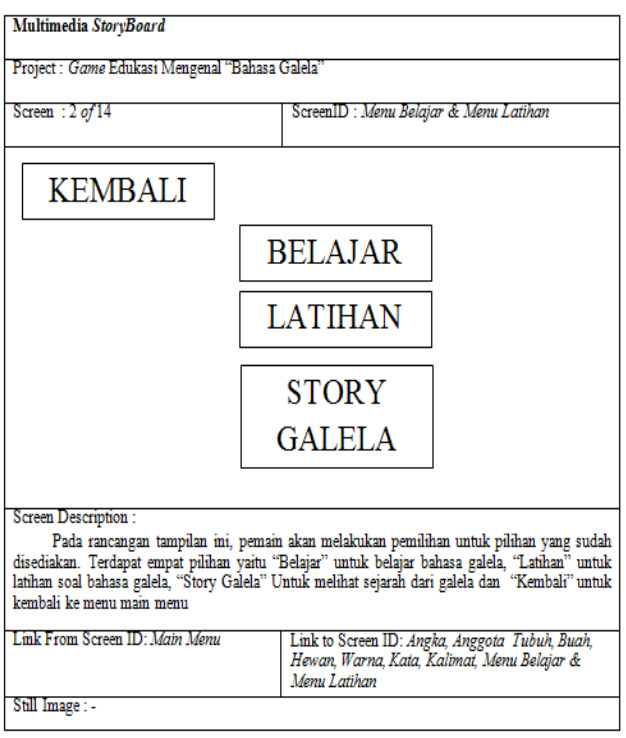

Gambar 2 Storyboard Menu Belajar \& Menu Latihan

2. UML Diagram

a. Use case diagram

Use case diagram digunakan untuk merepresentasikan interaksi antara pemain dengan game. Use case diagram dari game edukasi $O$ 'Galelano dapat dilihat pada gambar 3.

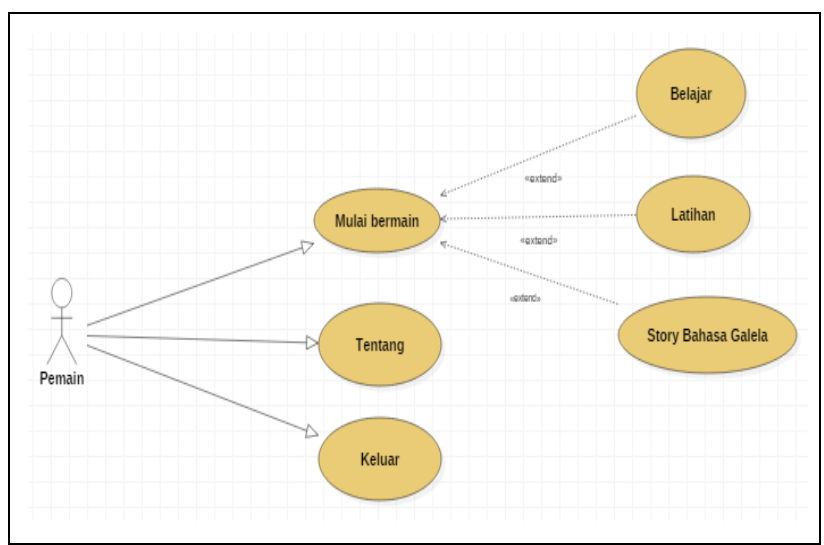

Gambar 3 Use Case Diagram Game Edukasi O'Galelano 


\section{Use Case Spesification : Mulai Bermain}

Brief Description : : Use case ini digunakan oleh user dalam memilih menu, dimana terdapat 2 menu yaitu menu belajar dan menu latihan

Basic Flow Events $\quad$ : dapat dilihat pada tabel 1

Tabel 1 Basic Flow Events mulai bermain

\begin{tabular}{|c|c|}
\hline Actor Action & System Response \\
\hline $\begin{array}{l}\text { 1. Use case dimulai } \\
\text { ketika } \text { user memilih } \\
\text { mulai bermain }\end{array}$ & $\begin{array}{l}\text { 2. } \text { Sistem akan } \\
\text { menampilkan menu } \\
\text { belajar dan menu latihan }\end{array}$ \\
\hline $\begin{array}{l}\text { 3. User memilih salah } \\
\text { satu menu }\end{array}$ & \\
\hline
\end{tabular}

Use Case Spesification : Belajar

Brief Description : : Use case ini digunakan oleh user dalam memilih kategori mana yang akan dimainkan.

Basic Flow Events $\quad$ : dapat dilihat pada tabel 2

Tabel 2 Basic Flow Events belajar

\begin{tabular}{|l|l|}
\hline \multicolumn{1}{|c|}{ Actor Action } & \multicolumn{1}{|c|}{ System Response } \\
\hline $\begin{array}{l}\text { 1. Use case dimulai } \\
\text { ketika } \text { user memilih } \\
\text { menu belajar }\end{array}$ & \begin{tabular}{l} 
2. $\begin{array}{l}\text { Sistem akan } \\
\text { menampilkan kategori- } \\
\text { kategori yang ada dalam } \\
\text { menu belajar }\end{array}$ \\
\hline $\begin{array}{l}\text { 3. User memilih salah } \\
\text { satu kategori }\end{array}$
\end{tabular} \\
$\begin{array}{l}\text { Use Case Spesification } \\
\text { Brief Description }\end{array}$ \\
$\begin{array}{l}\text { : Use case ini digunakan oleh } \\
\text { latihan dalam memilih menu }\end{array}$
\end{tabular}

Basic Flow Events : dapat dilihat pada tabel 3

Tabel 3 Basic Flow Events Latihan

\begin{tabular}{|c|c|}
\hline Actor Action & System Response \\
\hline $\begin{array}{l}\text { 1. Use case dimulai } \\
\text { ketika user memilih } \\
\text { menu latihan }\end{array}$ & $\begin{array}{l}\text { 2. Sistem akan } \\
\text { menampilkan soal - soal } \\
\text { latiham }\end{array}$ \\
\hline $\begin{array}{l}\text { 3. User menekan } \\
\text { tombol benar dan } \\
\text { salah untuk } \\
\text { menjawab soal - soal } \\
\text { latihan }\end{array}$ & $\begin{array}{l}\text { 4. Sistem akan } \\
\text { menampilkan jawaban } \\
\text { yang benar dan jawaban } \\
\text { yang salah }\end{array}$ \\
\hline
\end{tabular}

Use Case Spesification : Story Bahasa Galela

Brief Description : Use case ini digunakan oleh user dalam memilih menu story bahasa galela

Tabel 4 Basic Flow Events Story Bahasa Galela

\begin{tabular}{|c|c|}
\hline \multicolumn{1}{|c|}{ Actor Action } & \multicolumn{1}{|c|}{ System Response } \\
\hline $\begin{array}{l}\text { 1. Use case dimulai ketika user } \\
\text { memilih menu story bahasa galela }\end{array}$ & $\begin{array}{l}\text { 2. Sistem akan menampilkan cerita } \\
\text { bahasa galela }\end{array}$ \\
\hline 3. User menekan tombol peta galela & $\begin{array}{l}\text { 4. Sistem akan menampilkan peta } \\
\text { galela }\end{array}$ \\
\hline
\end{tabular}

Use Case Spesification : Tentang

Brief Description : Use case ini digunakan oleh user untuk mengetahui informasi aplikasi seperti identitas aplikasi pembuat aplikasi.

Basic Flow Events : dapat dilihat pada tabel 5

Tabel 5 Basic Flow Events Tentang

\begin{tabular}{|l|l|}
\hline \multicolumn{1}{|c|}{ Actor Action } & \multicolumn{1}{c|}{ System Response } \\
\hline $\begin{array}{l}\text { 1. Use case dimulai } \\
\text { ketika } \text { user memilih } \\
\text { menu tentang }\end{array}$ & $\begin{array}{l}\text { 2. } \begin{array}{l}\text { Sistem akan } \\
\text { menampilkan informasi } \\
\text { aplikasi }\end{array} \\
\text { 3. User membaca } \\
\text { informasi aplikasi }\end{array}$ \\
\hline
\end{tabular}

Use Case Spesification : Keluar

Brief Description : Use case ini digunakan oleh user untuk keluar dari aplikasi

Basic Flow Events : dapat dilihat pada tabel 6

Tabel 6 Basic Flow Events Keluar

\begin{tabular}{|c|c|}
\hline Actor Action & System Response \\
\hline $\begin{array}{l}\text { 1. Use case dimulai } \\
\text { ketika user memilih } \\
\text { menu keluar }\end{array}$ & $\begin{array}{l}\text { 2. Sistem otomatis } \\
\text { menghentikan jalannya } \\
\text { aplikasi }\end{array}$ \\
\hline $\begin{array}{l}\text { 3. User keluar dari } \\
\text { aplikasi }\end{array}$ & \\
\hline
\end{tabular}

b. Activity Diagram

Activity Diagram menggambarkan berbagai alur kegiatan secara umum yang ada didalam game, mulai dari awal dimulainya game, decision yang akan terjadi dan sampai berakhirnya.

\section{Activity Diagram Menu Belajar}

Ketika user memilih menu belajar, maka sistem akan menampilkan kategori - kategori dari angka, anggota tubuh, hewan, buah, warna, kata dan kalimat yang akan dimainkan. 


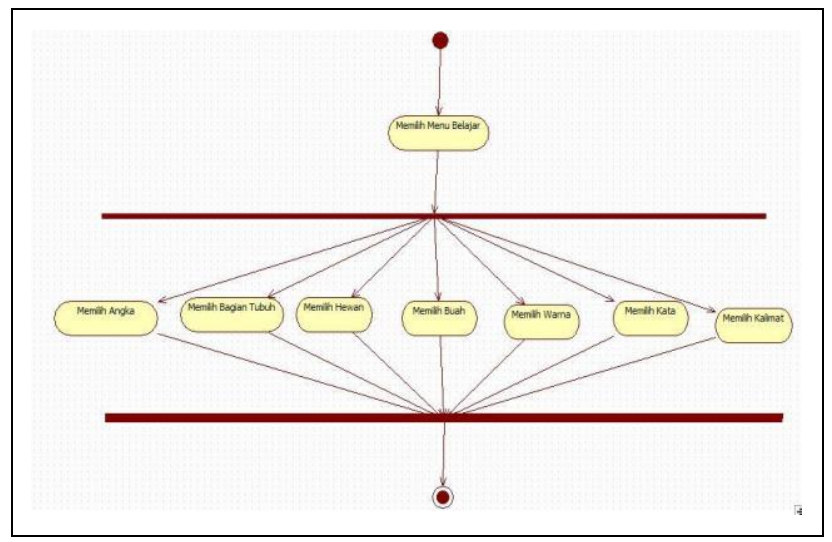

Gambar 4, Activity Diagram Menu Belajar

\section{Activity Diagram Menu Latihan}

Ketika user memilih menu latihan, maka sistem akan menampilka soal - soal latihan dari setiap kategori yang telah di mainkan pada menu belajar.

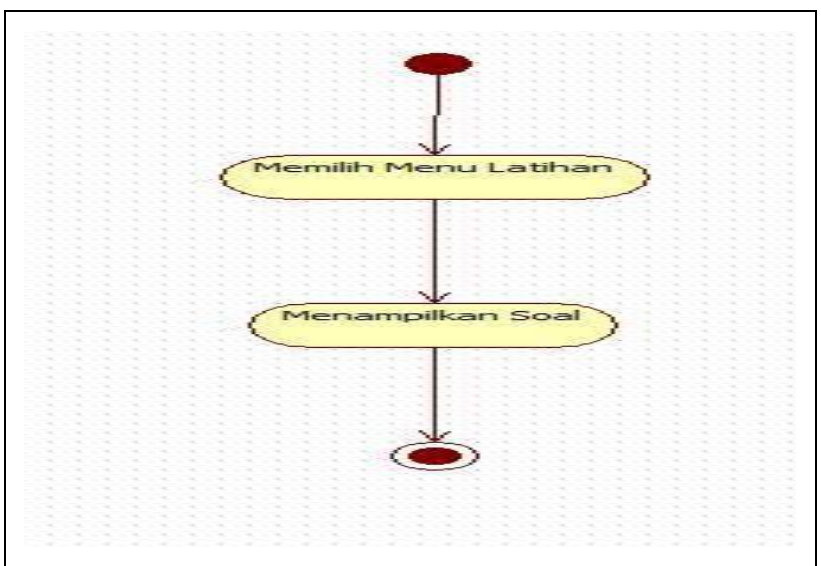

Gambar 5 Activity Diagram Menu Latihan

\section{Activity Diagram Menu Story Galela}

Ketika user memilih menu story galela, maka sistem akan menampilkan cerita tentang bahasa galela dan juga terdapat peta dari kecamatan galela.

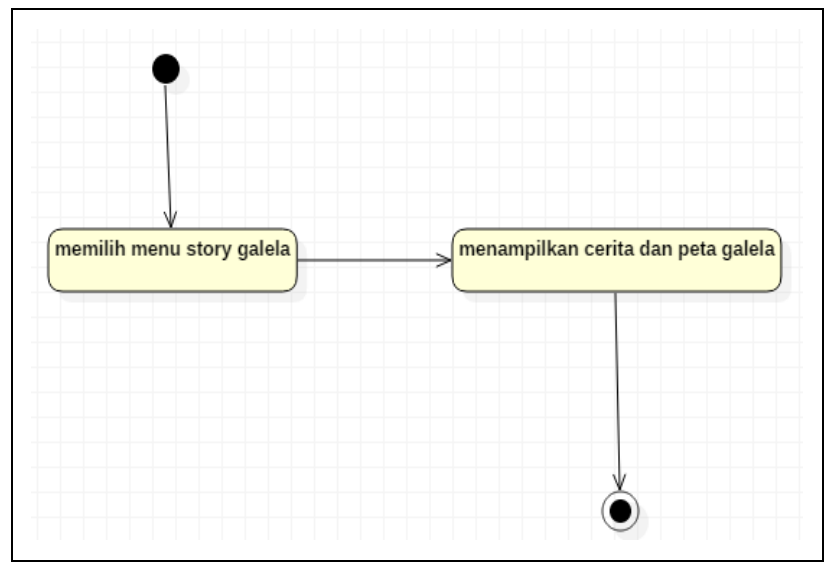

Gambar 6 Activity Diagram Menu Story Galela

\section{HASIL DAN PEMBAHASAN}

\section{A. Hasil Tampilan Aplikasi O’Galelano}

1. Tampilan Icon Aplikasi

Nama dari aplikasi game edukasi ini adalah O'Galelano. O'Galelano diambil dari bahasa galela yang berarti "Dari Galela", tampilan ini berfungsi untuk melihat dari icon aplikasi $O$ 'Galelano yang telah diinstal di smartphone. Tampilan dari icon aplikasi O'Galelano dapat dilihat pada gambar 8 .

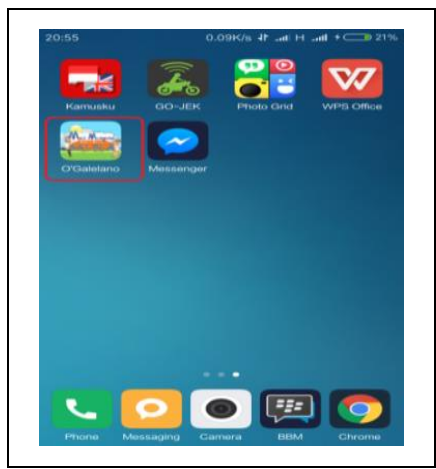

Gambar 8 Tampilan Icon Aplikasi O’Galelano

\section{Tampilan Menu Utama}

Tampilan ini berfungsi untuk melihat tampilan menu utama dari aplikasi O'Galelano yang telah diinstal di smartphone, pada tampilan ini terdapat menu mulai bermain, menu tentang deskripsi aplikasi dan menu keluar. Tampilan menu utama dari aplikasi O'Galelano dapat dilihat pada gambar 9.

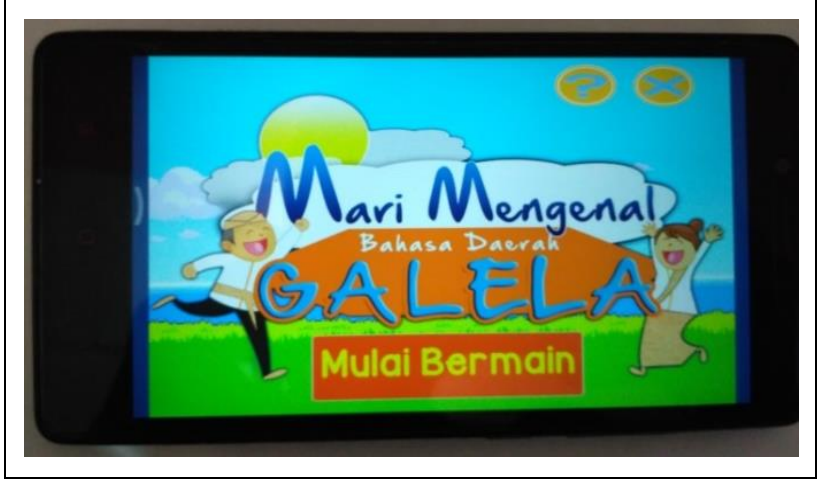

Gambar 9 Tampilan Menu Utama Aplikasi O'Galelano

\section{Tampilan Menu Mulai Bermain}

Screen menu mulai bermain pemain dapat memilih menu "Belajar" untuk masuk kehalaman pembelajaran sesuai kategori yang dipilih kemudian dilanjutkan dengan permainan di menu "Latihan" pemain harus menjawab soal-soal latihan dengan benar, soal - soal yang ada pada menu latihan ini adalah gabungan soal kategori - kategoi yang terdapat pada menu "Belajar". Implementasi screen menu kategori pada aplikasi $O$ 'Galelano ini dapat dilihat pada gambar 10 


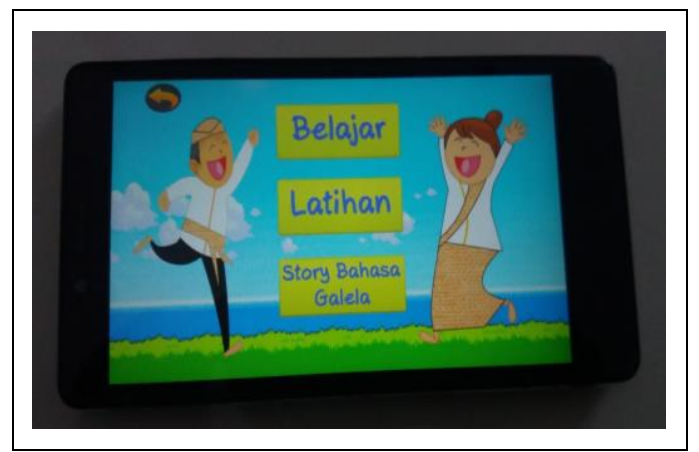

Gambar 10 Tampilan Menu Mulai Bermain

4. Tampilan Menu Belajar

Screen menu belajar dalam aplikasi O'Galelano muncul ketika button "Belajar" pada Menu Mulai Bermain ditekan. Screen ini untuk memilih kategori bahasa galela yang ingin dipelajari. Implementasi screen menu belajar pada aplikasi $O^{\prime}$ Galelano dapat dilihat pada gambar 11.

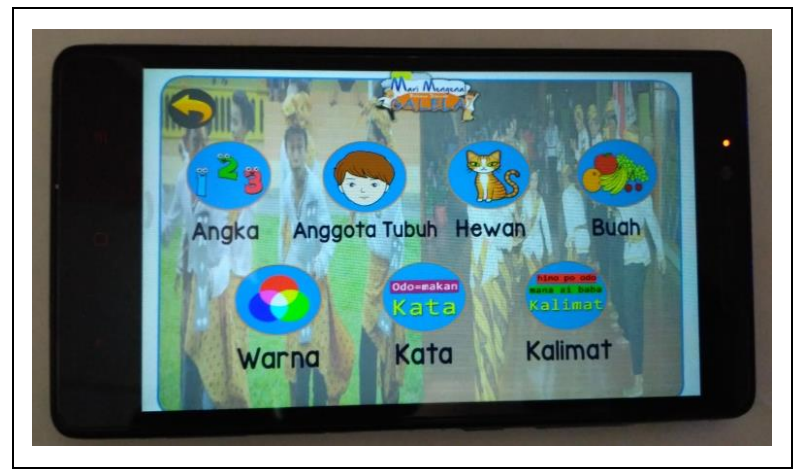

Gambar 11 Tampilan Menu Belajar

\section{Tampilan Pembelajaran}

Tampilan pembelajaran ini menampilkan kategori yang sebelumnya telah dipilih. Terdapat gambar serta audio cara pengucapan bahasa galela yang benar. implementasi tampilan pembelajaran belajar pada aplikasi $O^{\prime}$ Galelano dapat dilihat pada gambar 12

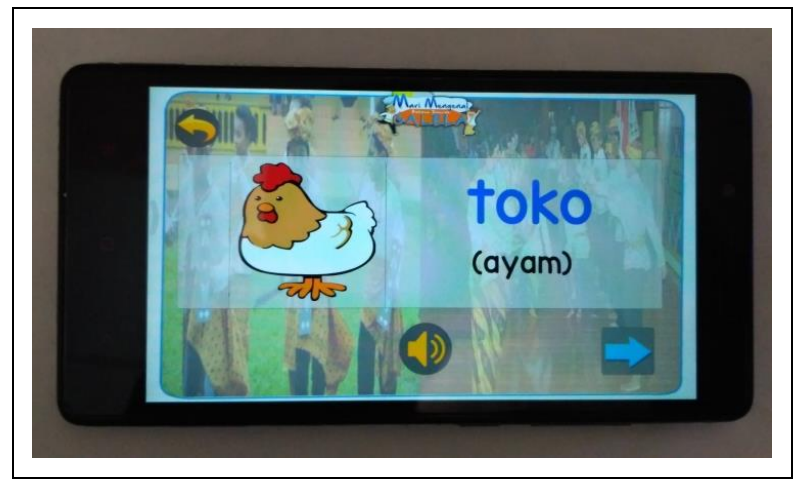

Gambar 12 Tampilan Pembelajaran

6. Tampilan Menu Latihan

Tampilan menu latihan merupakan tampilan soal - soal latihan yang muncul setelah pembelajaran selesai dilakukan. Pada menu latihan ini pemain akan menjawab soal - soal yang tersedia di menu latihan. Terdapat sepuluh soal yang diacak, dan soal - soal tersebut gabungan dari kategori- kategori yang ada di menu belajar. Dan di menu latihan ini pemain tidak boleh menjawab salah, jika pemain menjawab salah maka permainan langsung berhenti dan langsung menampilkan hasil dari jawaban pemain. Dan juga terdapat tombol benar dan salah untuk membantu pemain menjawab soal - soal yang terdapat di menu latihan. Implementasi screen menu latihan pada aplikasi O'Galelano dapat dilihat pada gambar 13.

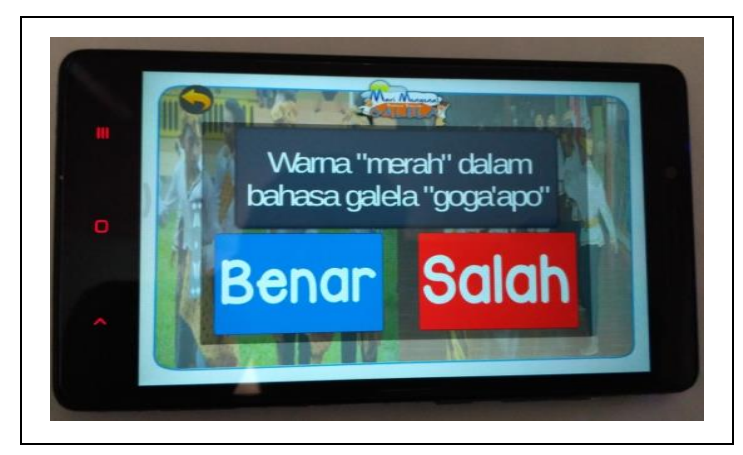

Gambar 13 Tampilan Soal-Soal Latihan

\section{Tampilan Menu Story Bahasa Galela}

Screen menu story bahasa galela ini akan menampilkan cerita dari bahasa galela dan pemain juga dapat melihat peta dari galela. Implementasi screen menu story bahasa galela pada aplikasi O'Galelano dapat dilihat pada gambar 14

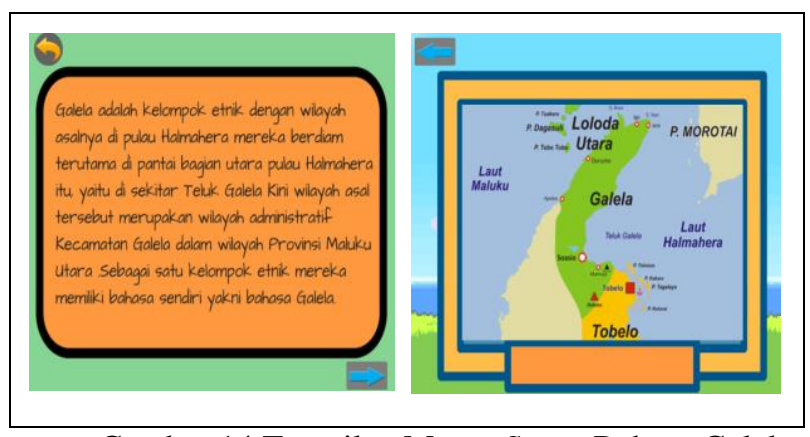

Gambar 14 Tampilan Menu Story Bahasa Galela

8. Tampilan Menu Tentang

Screen tentang ini akan menampilkan deskripsi singkat tentang game edukasi mari mengenal "Bahasa Galela". Implementasi screen tentang pada aplikasi $O^{\prime}$ Galelano dapat dilihat pada gambar 16

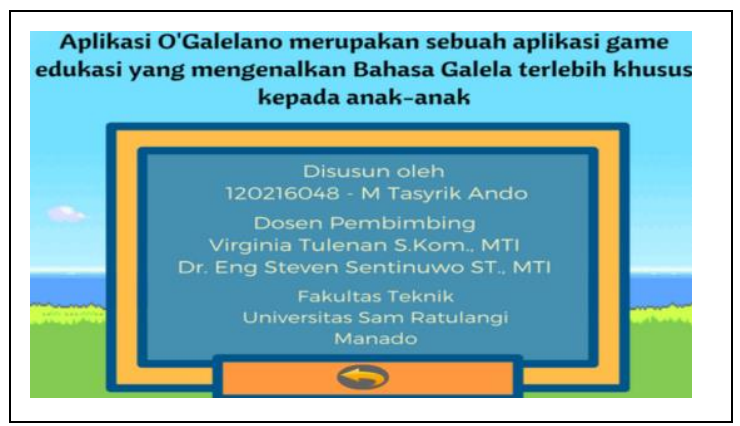

Gambar 15 Tampilan Menu Tentang 


\section{B. Tahap Pengujian Aplikasi O'Galelano}

Pengujian aplikasi merupakan tahapan yang bertujuan untuk menemukan kesalahan-kesalahan dalam sebuah aplikasi. Pengujian dilakukan untuk mengetahui apakah aplikasi yang telah dibangun dapat berjalan dengan baik (semua konten dan fungsinya) sesuai dengan yang telah dirancangkan oleh peneliti. Pengujian ini juga dapat meminimalisir kesalahan-kesalahan yang terjadi yang dapat menimbulkan ketidaknyamanan pengguna dalam menggunakan aplikasi.

Pada tahap ini peneliti menggunakan metode pengujian black box. Dengan menggunakan metode black box ini peneliti bertujuan untuk menentukan langkah-langkah dalam pengujian dan memeriksa kesesuaian hasil output dan tidak ada error yang didapati dari setiap scene, tombol (button). Hasil dari pengujian ini dapat dilihat dalam bentuk tabel.

Tabel 7 Pengujian Halaman Mulai Bermain (scene mulaibermain)

\begin{tabular}{|c|c|c|c|c|c|}
\hline No & $\begin{array}{c}\text { Antarmu } \\
\text { ka yang } \\
\text { diuji }\end{array}$ & $\begin{array}{c}\text { Bagian } \\
\text { antarmu } \\
\text { ka yang } \\
\text { diuji }\end{array}$ & $\begin{array}{c}\text { Skenari } \\
\text { o } \\
\text { penguji } \\
\text { an }\end{array}$ & $\begin{array}{c}\text { Hasil yang } \\
\text { diharapka } \\
\mathbf{n}\end{array}$ & $\begin{array}{c}\text { Hasil } \\
\text { penguji } \\
\text { an }\end{array}$ \\
\hline 1 & $\begin{array}{l}\text { Scene } \\
\text { mulai } \\
\text { bermain }\end{array}$ & $\begin{array}{l}\text { Button } \\
\text { Menu } \\
\text { Belajar }\end{array}$ & $\begin{array}{l}\text { User } \\
\text { menekan } \\
\text { button } \\
\text { Menu } \\
\text { Belajar }\end{array}$ & $\begin{array}{l}\text { Dapat } \\
\text { menampilk } \\
\text { an scene } \\
\text { menu } \\
\text { belajar }\end{array}$ & Berhasil \\
\hline 2 & $\begin{array}{l}\text { Scene } \\
\text { mulai } \\
\text { bermain }\end{array}$ & $\begin{array}{l}\text { Button } \\
\text { Menu } \\
\text { Latihan }\end{array}$ & $\begin{array}{l}\text { User } \\
\text { menekan } \\
\text { button } \\
\text { Menu } \\
\text { Latihan }\end{array}$ & $\begin{array}{l}\text { Dapat } \\
\text { menampilk } \\
\text { an scene } \\
\text { menu } \\
\text { latihan }\end{array}$ & Berhasil \\
\hline 3 & $\begin{array}{l}\text { Scene } \\
\text { mulai } \\
\text { bermain }\end{array}$ & $\begin{array}{l}\text { Button } \\
\text { Menu } \\
\text { Story } \\
\text { Bahasa } \\
\text { Galela }\end{array}$ & $\begin{array}{l}\text { User } \\
\text { menekan } \\
\text { button } \\
\text { Menu } \\
\text { Bahasa } \\
\text { Galela }\end{array}$ & $\begin{array}{l}\text { Dapat } \\
\text { menampilk } \\
\text { an scene } \\
\text { menu story } \\
\text { bahasa } \\
\text { galela }\end{array}$ & Berhasil \\
\hline
\end{tabular}

Hasil pengujian scene mulai bermain (lihat tabel 7) menunjukkan bahwa scene mulai bermain sudah berjalan dengan baik dan memberikan hasil sesuai yang diharapkan

Tabel 8 Pengujian Halaman Menu Belajar (scene menubelajar)

\begin{tabular}{|c|l|l|l|l|c|}
\hline $\begin{array}{c}\text { No } \\
\cdot\end{array}$ & $\begin{array}{l}\text { Antarmu } \\
\text { ka yang } \\
\text { diuji }\end{array}$ & $\begin{array}{c}\text { Bagian } \\
\text { antarmu } \\
\text { ka yang } \\
\text { diuji }\end{array}$ & $\begin{array}{c}\text { Skenari } \\
\text { o } \\
\text { penguji } \\
\text { an }\end{array}$ & $\begin{array}{c}\text { Hasil } \\
\text { yang } \\
\text { diharapka } \\
\mathrm{n}\end{array}$ & $\begin{array}{c}\text { Hasil } \\
\text { pengujia } \\
\mathrm{n}\end{array}$ \\
\hline 1 & $\begin{array}{l}\text { Scene } \\
\text { menu } \\
\text { belajar }\end{array}$ & $\begin{array}{l}\text { Button } \\
\text { Angka }\end{array}$ & $\begin{array}{l}\text { User } \\
\text { meneka } \\
\text { n button } \\
\text { Angka }\end{array}$ & $\begin{array}{l}\text { Dapat } \\
\text { menampil } \\
\text { kan scene } \\
\text { angka }\end{array}$ & Berhasil \\
\hline 2 & $\begin{array}{l}\text { Scene } \\
\text { menu } \\
\text { belajar }\end{array}$ & $\begin{array}{l}\text { Button } \\
\text { Anggota } \\
\text { Tubuh }\end{array}$ & $\begin{array}{l}\text { User } \\
\text { meneka } \\
\text { n button } \\
\text { Anggot } \\
\text { a Tubuh }\end{array}$ & $\begin{array}{l}\text { Dapat } \\
\text { menampil } \\
\text { kan scene } \\
\text { anggota } \\
\text { tubuh }\end{array}$ & $\begin{array}{c}\text { Bersuda } \\
\text { hasil }\end{array}$ \\
\hline 3 & $\begin{array}{l}\text { Scene } \\
\text { menu } \\
\text { belajar }\end{array}$ & $\begin{array}{l}\text { Button } \\
\text { Hewan }\end{array}$ & $\begin{array}{l}\text { User } \\
\text { meneka } \\
\text { n button } \\
\text { Hewan }\end{array}$ & $\begin{array}{l}\text { Dapat } \\
\text { menampil } \\
\text { kan scene } \\
\text { hewan }\end{array}$ & Berhasil \\
\hline 4 & Scene & Button & User & Dapat & Berhasil \\
\hline
\end{tabular}

\begin{tabular}{|c|l|l|l|l|l|}
\hline & $\begin{array}{l}\text { menu } \\
\text { belajar }\end{array}$ & Buah & $\begin{array}{l}\text { meneka } \\
\mathrm{n} \text { button } \\
\text { Buah }\end{array}$ & $\begin{array}{l}\text { menampil } \\
\text { kan scene } \\
\text { buah }\end{array}$ & \\
\hline 5 & $\begin{array}{l}\text { Scene } \\
\text { menu } \\
\text { belajar }\end{array}$ & $\begin{array}{l}\text { Button } \\
\text { Warna }\end{array}$ & $\begin{array}{l}\text { User } \\
\text { meneka } \\
\text { n button } \\
\text { Warna }\end{array}$ & $\begin{array}{l}\text { Dapat } \\
\text { menampil } \\
\text { kan scene } \\
\text { warna }\end{array}$ & Berhasil \\
\hline 6 & $\begin{array}{l}\text { Scene } \\
\text { menu } \\
\text { belajar }\end{array}$ & $\begin{array}{l}\text { Button } \\
\text { Kata }\end{array}$ & $\begin{array}{l}\text { User } \\
\text { meneka } \\
\text { n button } \\
\text { Kata }\end{array}$ & $\begin{array}{l}\text { Dapat } \\
\text { menampil } \\
\text { kan scene } \\
\text { kata }\end{array}$ & Berhasil \\
\hline 7 & $\begin{array}{l}\text { Scene } \\
\text { menu } \\
\text { belajar }\end{array}$ & $\begin{array}{l}\text { Button } \\
\text { Kalimat }\end{array}$ & $\begin{array}{l}\text { User } \\
\text { meneka } \\
\text { n button } \\
\text { Kalimat }\end{array}$ & $\begin{array}{l}\text { Dapat } \\
\text { menampil } \\
\text { kan scene } \\
\text { kalimat }\end{array}$ & Berhasil \\
\hline
\end{tabular}

Hasil pengujian scene menu belajar (lihat tabel 8) menunjukkan bahwa scene menu belajar sudah berjalan dengan baik dan memberikan hasil sesuai yang diharapkan

Tabel 9Pengujian Halaman Menu Latihan (scene Latihan)

\begin{tabular}{|c|c|c|c|c|c|}
\hline No & $\begin{array}{c}\text { Antarmu } \\
\text { ka yang } \\
\text { diuji }\end{array}$ & $\begin{array}{c}\text { Bagian } \\
\text { antarm } \\
\text { uka } \\
\text { yang } \\
\text { diuji }\end{array}$ & $\begin{array}{l}\text { Skenario } \\
\text { pengujian }\end{array}$ & $\begin{array}{c}\text { Hasil } \\
\text { yang } \\
\text { diharap } \\
\text { kan }\end{array}$ & $\begin{array}{c}\text { Hasil } \\
\text { pengujia } \\
\mathrm{n}\end{array}$ \\
\hline 1 & $\begin{array}{l}\text { Scene } \\
\text { Latihan }\end{array}$ & $\begin{array}{l}\text { Button } \\
\text { Latiha } \\
\mathrm{n}\end{array}$ & $\begin{array}{l}\text { User } \\
\text { menekan } \\
\text { button } \\
\text { latihan }\end{array}$ & $\begin{array}{l}\text { Dapat } \\
\text { menam } \\
\text { pilkan } \\
\text { scene } \\
\text { Kalimat }\end{array}$ & Berhasil \\
\hline 2 & $\begin{array}{l}\text { Scene } \\
\text { Latihan }\end{array}$ & $\begin{array}{l}\text { Button } \\
\text { Suara }\end{array}$ & $\begin{array}{l}\text { User } \\
\text { menekan } \\
\text { button } \\
\text { suara }\end{array}$ & $\begin{array}{l}\text { Dapat } \\
\text { menden } \\
\text { garkan } \\
\text { suara } \\
\text { kalimat } \\
\text { dalam } \\
\text { bahasa } \\
\text { galela }\end{array}$ & Bershasil \\
\hline 3 & $\begin{array}{l}\text { Scene } \\
\text { Latihan }\end{array}$ & $\begin{array}{l}\text { Button } \\
\text { Benar }\end{array}$ & $\begin{array}{l}\text { User } \\
\text { menekan } \\
\text { button } \\
\text { benar }\end{array}$ & $\begin{array}{l}\text { Dapat } \\
\text { menam } \\
\text { pilkan } \\
\text { jawaba } \\
\text { n yang } \\
\text { benar } \\
\text { atau } \\
\text { salah }\end{array}$ & Berhasil \\
\hline 4 & $\begin{array}{l}\text { Scene } \\
\text { Latihan }\end{array}$ & $\begin{array}{l}\text { Button } \\
\text { Salah }\end{array}$ & $\begin{array}{l}\text { User } \\
\text { menekan } \\
\text { button } \\
\text { salah }\end{array}$ & $\begin{array}{l}\text { Dapat } \\
\text { menam } \\
\text { pilkan } \\
\text { jawaba } \\
\text { n yang } \\
\text { benar } \\
\text { atau } \\
\text { salah }\end{array}$ & Berhasil \\
\hline 5 & $\begin{array}{l}\text { Scene } \\
\text { Latihan }\end{array}$ & Button & $\begin{array}{l}\text { User } \\
\text { menekan } \\
\text { button } \\
\text { "next" }\end{array}$ & $\begin{array}{l}\text { Dapat } \\
\text { menam } \\
\text { pilkan } \\
\text { gambar } \\
\text { kalimat } \\
\text { selanjut } \\
\text { nya }\end{array}$ & Berhasil \\
\hline
\end{tabular}

Hasil pengujian scene menu latihan (lihat tabel 9) menunjukkan bahwa scene menu latihan sudah berjalan dengan baik dan memberikan hasil sesuai yang diharapkan 


\section{A. Kesimpulan}

Dari penelitian yang dilakukan diperoleh kesimpulan:

1. Telah berhasil dibuat Aplikasi Game Edukasi Pengenalan Bahasa Daerah Galela Untuk Anak Tingkat Sekolah Dasar

2. Game dimainkan satu orang player atau single player.

3. Permainan ini dikhususkan pada anak - anak dari kelas $1-6 \mathrm{SD}$, namun bisa dimainkan juga oleh orang dewasa.

4. Game edukasi O'Galelano ini memberikan pembelajaran kepada anak - anak tentang Bahasa Daerah Galela.

5. Game edukasi $O^{\prime}$ Galelano ini sangat mudah untuk dimainkan. Game edukasi O'Galelano dapat diinstal di smartphone mulai dari android versi 4.0 Jelly Bean sampai dengan android versi terbaru.

6. Game edukasi O'Galelano terdapat kategorikategori yang harus dipelajari diantaranya, Kategori Angka, Anggota Tubuh, Nama Hewan, Nama Buah, Warna, Kata dan Kalimat.

7. Penulis membuat game edukasi yang dikemas secara modern, yaitu dengan smartphone Android, agar pengguna lebih mudah untuk memainkan game edukasi tersebut.

8. Berdasarkan kuisioner implementasi game yang diisi oleh 40 orang responden, dapat simpulkan dari segi kepuasan pengguna secara umum game O'Galelano bisa diterapkan karena sangat bermanfaat untuk menambah pengetahuan tentang bahasa galela untuk anak tingkat sekolah dasar.

\section{B. Saran}

Setelah dilakukan penelitian ini, disarankan:

1. Dalam pengembangan game edukasi $O$ 'Galelano hanya dapat dimainkan secara offline, harapan ke depannya semoga aplikasi ini dapat dikembangkan lebih menarik lagi dengan menambahkan animasi agar dapat dipergunakan secara luas di internet.

2. Game ini diharapkan tidak hanya berbasis OS android saja, tetapi bisa OS yang lain.

\section{DAFTAR PUSTAKA}

[1] Dinas Pariwisata dan Kebudayaan Kabupaten Halmahera Utara. 2015.Lomba Seni Budaya Festival Canga Hibualamo. Diambil kembali dari Halmaherautara.com:

http://www.halmaherautara.com ‘

[2] Fullerton, T. 2008. Game Design Workshop, Second Edition : A Playcentric Approach to Creating Innovative Games (Gama Network Series). Morgan Kaufmann

[3] Gunarsa, S. D. 2006. Dasar dan teori perkembangan anak. Gunung Mulia. Jakarta
[4] Intan Hikmah. 2016. Pembuatan Game Edukasi "English For Fun" untuk Anak Kelas 1-2 SD Berbasis Android Menggunakan Unity 3D. Skripsi Program DIII Fakultas MIPA Universitas Sebelas Maret. Surakarta

[5] Iskandar Sukini. 2009. "Bahasa Indonesia 1". Pusat Pebukuan, Departemen Pendidikan Nasional. Jakarta.

[6] Lewis, Michael \& Jacobson, Jeffrey. 2002. Game Engines in Scientific Research. Communications Of The Acm, No. 1 Vol. 45, h. 27- 31.

[7] Michello Suwandi, 2014. Protitpe Game Musik Bambu Menggunakan Engine Unity 3D. Skripsi Program S1 Fakultas Teknik Universitas Sam Ratulangi. Manado.

[8] Mandagie, R.J.M dkk. 2006. Panduan Penulisan KTIS Fakultas Teknik UNSRAT. Fakultas Teknik Universitas Sam Ratulangi. Manado.

[9] Nugroho, Adi. 2010. Rekayasa Perangkat Lunak Menggunakan UML dan Java. Penerbit Andi. Yogyakarta.

[10] Pressman, R. S. 2010. Rekayasa Perangkat Lunak - Pendekatan Praktisi. Edisi 7 Penerbit Andi. Yogyakarta

[11] Schell, Jesse. 2008. The Art of Game Design - A Book of Lenses. Morgan Kaufmann Publisher Burlington.

[12] Suyanto, M. 2004. Analisis dan Desain Aplikasi Multimedia untuk Pemasaran. Penerbit Andi. Yogyakarta.

[13] Sudaryono. (2015). Metodologi Riset di Bidang TI (Panduan Praktis, Teori dan Contoh Kasus). Yogyakarta: Penerbit ANDI.

\section{SEKILAS TENTANG PENULIS}

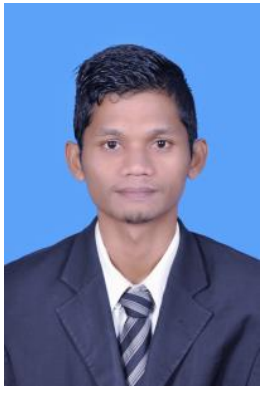

Sekilas tentang penulis dengan nama lengkap $M$ Tasyrik Ando, pada tanggal 17 Mei 1994 lahir di Galela, Kabupaten Halmahera Utara Provinsi Maluku Utara. Penulis merupakan anak ke-3 dari 2 bersaudara dengan latar belakang pendidikan Sekolah Dasar SD Negeri Inpres Soasio, Setelah lulus Melanjutkan ke Sekolah Menengah Pertama MTS Muhammadiyah Soasio Galela . Kemudian melanjutkan ke Sekolah Menengah Atas SMA Negeri 2 Halut dan dinyatakan lulus pada tahun 2012 lalu melanjutkan ke Perguruan Tinggi di Universitas Sam Ratulangi Manado dengan mengambil Jurusan Elektro Program Studi Teknik Informatika. Pada tahun 2015 bulan Juli, penulis membuat Skripsi demi memenuhi syarat memperoleh gelar Sarjana (S1) dengan penelitian berjudul "Rancang Bangun Aplikasi Game Edukasi Pengenalan Bahasa Daerah Galela untuk Anak Tingkat Sekolah Dasar" yang dibimbing oleh dua dosen pembimbing yaitu Dr. Eng. Steven R. Sentinuwo,ST.,MTI dan Virginia Tulenan, S.Kom,MTI serta pada tanggal 25 Oktober 2016 penulis resmi lulus dari Program Studi Teknik Informatika Jurusan Elektro Fakultas Teknik Universitas Sam Ratulangi Manado dan menyandang gelar Sarjana Komputer . 